\title{
Assessment of cardiovascular physiology using magnetic resonance myocardial stress testing reveals impaired contractile reserve in patients with cirrhotic cardiomyopathy
}

\author{
Francisco Sampaio ${ }^{1,2}$, Pablo Lamata ${ }^{3}$, Nuno Bettencourt ${ }^{1,2}$, Sophie-Charlotte Alt ${ }^{4}$, Nuno D Ferreira ${ }^{1}$, \\ Johannes T Kowallick ${ }^{5,6}$, Joana Pimenta ${ }^{2}$, Shelby Kutty ${ }^{7}$, Jose Fraga ${ }^{8}$, Paulo Bettencourt ${ }^{2}$, Vasco Gama ${ }^{1}$, \\ Andreas Schuster ${ }^{9,10^{*}}$
}

From 18th Annual SCMR Scientific Sessions

Nice, France. 4-7 February 2015

\section{Background}

Liver cirrhosis has been shown to affect cardiac performance. However cardiac dysfunction may only be revealed under stress conditions. The value of non-invasive stress tests in diagnosing cirrhotic cardiomyopathy is unclear since their ability to detect abnormalities has been inconsistent using different imaging modalities. We sought to investigate the response to pharmacological stimulation with dobutamine in patients with cirrhosis using cardiovascular magnetic resonance.

\section{Methods}

Thirty-six patients and eight controls were studied. Conventional volumetric and myocardial deformation parameter analysis using feature tracking at rest and during low to intermediate dose dobutamine stress were performed.

\section{Results}

Whilst volumetry based parameters were similar between patients and controls at rest, patients had a smaller increase in cardiac output during stress $(2.2 \mathrm{l} / \mathrm{min}$ vs. $3.8 \mathrm{l} / \mathrm{min}$ ), $\mathrm{p}=0.015)$. Chronotropic response was not different in the two groups ( $24 \mathrm{bpm}$ vs $25 \mathrm{bpm}, \mathrm{p}=0.44$ ). Ejection fraction increase was impaired in patients during $10 \mu \mathrm{g} / \mathrm{Kg} / \mathrm{min}$ dobutamine as compared to controls $(6.9 \%$ vs. $16.5 \%, \mathrm{p}=0.007)$, but not with $20 \mu \mathrm{g} / \mathrm{Kg} / \mathrm{min}(12.1 \%$ vs. $17.6 \%, \mathrm{p}=0.12)$. This was paralleled by an impaired

${ }^{9}$ Division of Imaging Sciences and Biomedical Engineering, The Rayne Institute, Kings College London, London, UK

Full list of author information is available at the end of the article improvement in circumferential strain with low dose (median percentual increase of $14.4 \%$ vs. $30.9 \%, \mathrm{p}=0.03$ ), but not with intermediate dose dobutamine (median percentual increase of $29.4 \%$ vs. $33.9 \%, p=0.54$ ). There was an impaired longitudinal strain increase in patients as compared to controls during low (median percentual increase of $6.6 \%$ vs $28.6 \%, p<0.001$ ) and intermediate dose dobutamine (median percentual increase of $2.6 \% \mathrm{vs}, 12.6 \%$ $\mathrm{p}=0.016$ ). Radial strain response to dobutamine was similar in patients and controls (median percentual increase of $7.7 \%(-2.4-15.2)$ vs $13.6 \%$ (5.7-26), $\mathrm{p}=0.11$ with $10 \mu \mathrm{g} / \mathrm{Kg} / \mathrm{min}$ of dobutamine and $4.3 \%(0.6-8.1)$ vs $3.1 \%$ (-0.2-9.3), $\mathrm{p}=0.82$ with $20 \mu \mathrm{g} / \mathrm{Kg} / \mathrm{min}$ of dobutamine).

\section{Conclusions}

Cirrhotic cardiomyopathy is characterized by an impaired cardiac pharmacological response that can be detected with magnetic resonance myocardial stress testing. Deformation analysis parameters may be more sensitive in identifying abnormalities in inotropic response to stress than conventional methods.

\section{Funding}

NA.
Authors' details
${ }^{1}$ Cardiology Department, Centro Hospitalar Gaia/Espinho, VN Gaia, Portugal. ${ }^{2}$ University of Porto Medical School, Porto, Portugal. ${ }^{3}$ Biomedical
Engineering, King's College London, London, UK. ${ }^{4}$ Department of Pediatric Cardiology and Intensive Care Medicine, Georg-August University, Göttingen, Germany. ${ }^{5}$ Institute for Diagnostic and Interventional Radiology, Georg- 
August University, Göttingen, Germany. ${ }^{6}$ German Centre for Cardiovascular Research, Göttingen, Germany. ${ }^{7}$ Children's Hospital and Medical Center, University of Nebraska Medical Center, Omaha, NE. ${ }^{8}$ Gatsroenterology Department, Centro Hospitalar Gaia/Espinho, VN Gaia, Portugal. ${ }^{9}$ Division of Imaging Sciences and Biomedical Engineering, The Rayne Institute, Kings College London, London, UK. ${ }^{10}$ Department of Cardiology and Pneumology, Georg-August University, Göttingen, Germany.

Published: 3 February 2015

doi:10.1186/1532-429X-17-S1-067

Cite this article as: Sampaio et al: Assessment of cardiovascular physiology using magnetic resonance myocardial stress testing reveals impaired contractile reserve in patients with cirrhotic cardiomyopathy. Journal of Cardiovascular Magnetic Resonance 2015 17(Suppl 1):Q67.

Submit your next manuscript to BioMed Central and take full advantage of:

- Convenient online submission

- Thorough peer review

- No space constraints or color figure charges

- Immediate publication on acceptance

- Inclusion in PubMed, CAS, Scopus and Google Scholar

- Research which is freely available for redistribution

Submit your manuscript at www.biomedcentral.com/submit 